
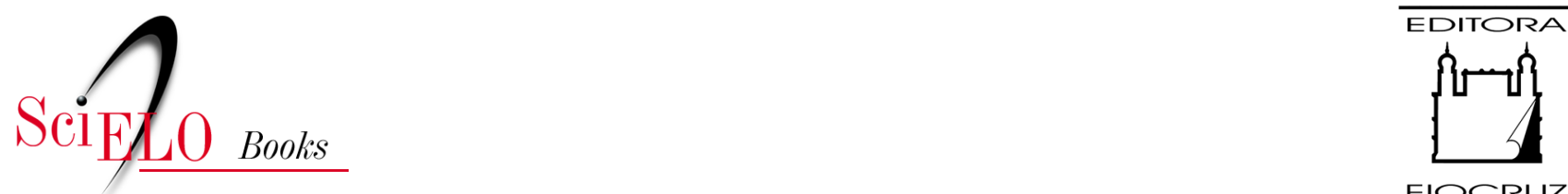

FIOCRUZ

\title{
Uma História do Dr. Naftale Katz (maio de 1998)
}

\author{
Virgínia Schall
}

\section{SciELO Books / SciELO Livros / SciELO Libros}

SCHALL, V. Uma História do Dr. Naftale Katz (maio de 1998). In: Contos de Fatos: histórias de Manguinhos [online]. Rio de Janeiro: Editora FIOCRUZ, 2001, pp. 77-84. ISBN: 978-85-7541-614-3. Available from: doi: $10.7476 / 9788575416143.0009$. Also available in ePUB from: http://books.scielo.org/id/hdq6f/epub/schall-9788575416143.epub.

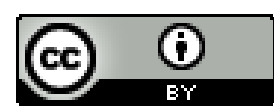

All the contents of this work, except where otherwise noted, is licensed under a Creative Commons Attribution $\underline{4.0 \text { International license. }}$

Todo o conteúdo deste trabalho, exceto quando houver ressalva, é publicado sob a licença Creative Commons Atribição 4.0. 


\section{Uma História do Dr. \\ Naftale Katz \\ (maio de 1998)}

A força da invenção reside num espírito preparado.

Jacques Chabannes

uando, em 1998, vim morar em Belo Horizonte, trabalhando no
Centro de Pesquisas René Rachou (CPqRR/Fiocruz), tornei-me vizinha de sala do Dr. Naftale Katz e chegou, então, a oportunidade de conversar melhor sobre a sua vida de pesquisas. Um caminho rico de realizações, seja para o avanço do conhecimento científico - sobretudo sobre a esquistossomose, área em que continua contribuindo -, seja para a gerência e liderança da pesquisa - como diretor do CPqRR por 12 anos, multiplicou a sua área física e aglutinou novos cientistas, ampliando a capacidade científica da Fiocruz em Minas Gerais.

Suas histórias brotam vivas e é preciso ter um raciocínio ágil para acompanhar o seu ritmo dinâmico e seu estilo franco e direto. Fala sempre o que lhe vem à mente, não segura as palavras. Os olhos dizendo tanto quanto as idéias, revelando entusiasmo e gosto pela carreira que escolheu. A conversa tece enredos que passeiam por inúmeras vielas, desde os relatos de seu próprio trabalho, a memória de histórias de outros cientistas e de importantes descobertas perpassadas pelo espírito crítico e incisivo, até (hum!) as delícias culinárias que é capaz de recriar com toques pessoais. Ele é um verdadeiro dínamo e poderia preencher páginas e mais páginas de vários livros contando e rememorando vivências e fatos da ciência e da 
vida de seus protagonistas. Entretanto, focalizarei aqui o relato de uma importante contribuição sua para a saúde pública, que se destaca pela sua repercussão internacional, por ter solucionado o problema de diagnóstico de uma doença que aflige mais de setenta países no mundo.

\section{Uma Noite, um Insight}

Voltemos um pouco no tempo. Vamos ao final da efervescente década de 70. Considerando o panorama de saúde da população brasileira daquele tempo, estamos diante de um quadro quase desolador. A figura do Jeca Tatu, criada por Monteiro Lobato, é uma realidade multiplicada por todo o país. Inúmeras verminoses, dentre tantos outros problemas de saúde (malária, febre amarela, doença de Chagas etc.), prejudicavam a olhos vistos os corpos e a energia de milhares de pessoas. Em relação à esquistossomose, doença estudada por Naftale desde os seus tempos de estudante de medicina, a situação era crítica. Nas áreas endêmicas, crianças e adultos atestavam, com suas enormes barrigas - sintoma que tornou a doença conhecida como 'barriga d'água' -, a presença e a severidade da parasitose.

O que a ciência oferecia então para enfrentar o problema? Muito pouco. Os métodos para diagnóstico, baseados em exame de fezes, ainda deixavam a desejar, pois podiam levar a resultados falsos ou pouco precisos. $\mathrm{O}$ tratamento ficava restrito a medicamentos com perigosos efeitos colaterais, requerendo a internação do paciente e, ainda assim, provocando até mortes. O controle dos caramujos vetores da doença também dependia da importação de caros produtos químicos, a maioria poluentes das águas onde eram aplicados. Naquela época, pensar em vacina para vermes - que ainda continua a mobilizar diversos grupos de pesquisa no mundo - era um desafio distante. Os problemas sociais e políticos eram também enormes. Assim, o saneamento básico, ainda hoje uma questão que depende das consciências políticas para ser tratada como prioridade, era um sonho remoto. 
Em relação ao diagnóstico, a OMS apoiava pesquisas que pudessem aperfeiçoar os métodos quantitativos do exame de fezes, para que estes obtivessem resultados mais precisos e confiáveis. Os métodos utilizados naquela época eram o de Stoll, o de Bell e o de Kato. Todos apresentavam problemas e careciam de aperfeiçoamento. No Brasil, alguns pesquisadores conduziam estudos nesta área, como o Prof. Frederico Simões Barbosa, que à época buscava aperfeiçoar o método de Lutz (sedimentação espontânea em água) de modo a torná-lo quantitativo. Por sua vez, Naftale Katz, trabalhando em áreas endêmicas de Minas, precisava de um método seguro e de fácil uso nas próprias localidades em que pesquisava. Na ocasião, seu trabalho de campo situava-se no nordeste de Minas, na região do Mucuri, em Tuparecê, onde a esquistossomose apresentava uma altíssima prevalência. Decidiram usar o método de Kato, o qual havia sido divulgado no mundo pelo pesquisador americano P. Beaver, de Nova Orleans, após uma visita que fizera ao Japão, onde tomara contato com o criador da técnica, o pesquisador japonês K. Kato. O Dr. Beaver traduziu o trabalho de Kato para o inglês e o distribuiu mundialmente. Por seu intermédio, no final de 1968 o CPqRR recebeu, em treinamento científico, um médico da Marinha, Dr. Larry Martin, o qual introduziu o método Kato no Brasil. Trabalhando na ocasião com outro pesquisador, Geraldo Chaia, Naftale já havia testado outros métodos de diagnóstico e concluído que a maioria apresentava deficiências. Considerou que o Kato parecia um bom método e decidiu avaliá-lo para uso nas áreas endêmicas. Entretanto, como um método quantitativo, o Kato requeria a pesagem das fezes em balanças sensíveis, para que fosse possível calcular o número de ovos por grama de fezes (oograma) e, assim, diagnosticar a severidade da doença em cada paciente. Naquele tempo usavam uma balança da Merker, a mais sensível de que dispunham.

Arrumaram o material de campo, um verdadeiro arsenal de laboratório, incluindo vidraria, frascos de coleta de fezes, a balança, reagentes, remédios para tratamento dos doentes etc. A viagem de Belo Horizonte a Tuparecê 
levava dez horas, vencendo estradas tortuosas de terra na camioneta do Centro. Ao chegar lá, após a cansativa jornada, prontos para iniciar o trabalho, uma surpresa desagradável: a balança não funcionava, talvez comprometida pela trepidação excessiva da estrada. A viagem estava perdida. Como fazer os exames quantitativos sem a balança? Dr. Naftale percebeu logo que a balança era o maior obstáculo para que o método pudesse ser usado em larga escala, sobretudo nas distantes e precárias áreas de maior endemicidade. $O$ incidente da viagem passou a agitar a sua mente e ele não descansaria até resolver aquele problema.

Pouco tempo antes, havia lido um trabalho de M. Layrisse e colaboradores, do Instituto Venezuelano de Investigações Científicas (Ivic). $O$ pesquisador descrevia o uso de uma seringa de 1 mililitro, cortada em um tamanho padronizado, para medir o volume de fezes. Com essa seringa, era aspirado 1 ou 2 centímetros de fezes, quantificando assim o volume, o que eliminava a necessidade de uma balança. Embora fosse um método de baixo custo, apresentava algumas desvantagens, pois a reutilização das seringas requeria muito tempo para higienização e ainda apresentava risco de contaminação do novo material com ovos de vermes minúsculos que pudessem restar após a limpeza. Além disso, a quantidade dosada era grande demais e demandava muito tempo para ser examinada.

Esse trabalho, entretanto, ficou na mente de Naftale e serviu de pista para que ele chegasse ao aperfeiçoamento do método Kato. Uma noite, imaginou o desenho da seringa ilustrada no trabalho lido e supôs que o diâmetro de sua abertura poderia ser encaixado perfeitamente sobre a lâmina usada no método Kato. Calculou que no diâmetro da abertura no centro da lâmina poderiam caber em torno de $40 \mathrm{mg}$ de fezes. Isso poderia ser feito com material barato, como o papelão. $O$ dia seguinte custou a chegar. Naftale queria logo pôr a sua idéia à prova. Chegou bem cedo ao Centro de Pesquisas, chamou o seu assistente de pesquisa, Adelu, contoulhe sobre a idéia e pediu-lhe que fosse até uma gráfica com o desenho que fizera. Adelu trouxe vários cartões de papelão, escolheram um para o 
ensaio, cortando-o em tamanho retangular $(3 \times 4 \mathrm{~cm})$ e espessura de 1,27 $\mathrm{mm}$. Fazendo-se uma abertura de 6 milímetros de diâmetro no centro do cartão, a ser perfurado na própria gráfica, era possível obter um padrão quantitativo ideal. Feito o cartão perfurado, este poderia ser colocado sobre a lâmina própria para o exame e então receber a quantidade certa de material para análise. De fato, a montagem funcionou e, ao estimarem a quantidade contida na abertura, esta pesou em torno de 43 miligramas. Com base neste peso, era só fazer uma regra de três direta e assim calcular a quantidade de ovos por grama de fezes. Fez comparações entre o material pesado na balança de precisão e o material medido com o cartão perfurado, e o índice de correlação foi muito alto. Dessa forma, os cartões perfurados passaram a ser usados na rotina do laboratório e nas pesquisas de campo, os quais eram descartáveis, de baixo custo e fácil utilização. Naftale apresentou o trabalho ao seu mestre, Dr. José Pellegrino (de quem fala com admiração e respeito profissional), o qual participou da redação da publicação, enriquecendo a discussão. O trabalho original foi publicado em 1972 na Revista do Instituto de Medicina Tropical de São Paulo, ${ }^{24}$ em inglês, e foi solicitado por pesquisadores do mundo inteiro. Assim surgia o método Kato-Katz, que foi desenvolvido como um kit, de modo a padronizar as medidas e evitar variabilidade no exame. Um distribuidor que vendia materiais científicos passou a produzi-lo e distribuí-lo. Por meio de um acordo, a OMS solicitou autorização e passou a distribuir o kit em todo o mundo, para os numerosos países endêmicos. O método foi testado por diversos pesquisadores em vários países, assim como no Japão, de onde se originara a técnica inicial, e concluiu-se que era o melhor, mais preciso e adequado. Foi introduzido na China em 1982 e ainda hoje continua sendo utilizado em larga escala mundo afora.

\footnotetext{
${ }^{24}$ KATZ, N.; CHAVES, A. \& PELLEGRINO, J. A simple device for quantitative stool thicksmear technique in schistosomiasis mansoni, Revista do Instituto de Medicina Tropical de São Paulo, 14(6): 397-400, 1972.
} 
Como se vê, diante da dificuldade encontrada, o pesquisador foi capaz de ir unindo idéias e fazer as associações certas, criando uma tecnologia simples e eficiente. É importante destacar também o papel da circulação da informação, que nesta história reúne vários pesquisadores: 0 americano que divulga o método Kato, do Japão para as mais distantes regiões; o próprio Kato, japonês; e o venezuelano cuja publicação inspirou Katz. Este último, brasileiro, compôs, como num quebra-cabeça cujas peças vão sendo pouco a pouco encaixadas, uma nova configuração funcional capaz de solucionar um problema e ajudar milhões de seres humanos espalhados pelos quatro cantos do planeta.

Aqui ainda cabe destacar as tantas outras contribuições de Katz para o enfrentamento da esquistossomose. Ele atualizou as estatísticas de prevalência da doença no Brasil; testou, na década de 70, as novas drogas até hoje usadas com sucesso no tratamento; orientou e formou vários pesquisadores; e participou de pesquisas que poderão resultar em vacinas para a fasciolose e, possivelmente, para a esquistossomose. 


\section{Dr. Naftale Katz ${ }^{25}$}

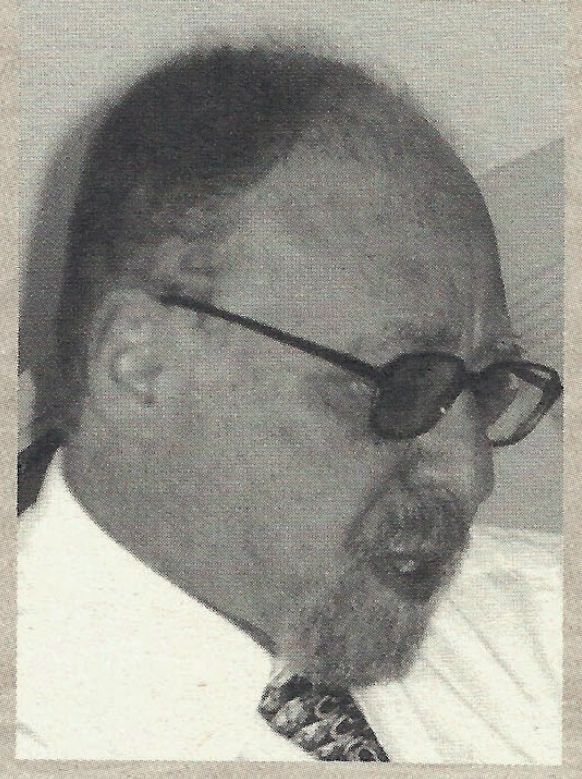

Dr. Naftale Katz nasceu em 1940, na cidade de Belo Horizonte, formando-se médico em 1964 pela Faculdade de Medicina da UFMG. Desde estudante ingressou na área de pesquisa, publicando o seu primeiro trabalho sobre esquistossomose no ano em que se formou. De 1964 até 1999 publicou 233 artigos em revistas nacionais e internacionais, destacandose a sua contribuição para a epidemiologia e o controle da esquistossomose no Brasil. Aperfeiçoou um método de diagnóstico para esquistossomose e outras verminoses (método Kato-Katz), o qual tem sido utilizado na maioria dos países endêmicos do mundo e é recomendado pela organização Mundial da saúde. Contribuiu também para o desenvolvimento e a avaliação das novas drogas para o tratamento da esquistossomose, por meio da realização de numerosos ensaios experimentais e clínicos. É um dos pesquisadores responsáveis pela descoberta de um antígeno protetor em animais contra a esquistossomose e a fasciolose, da qual detém, em conjunto com os demais autores, patente registrada no Brasil e em outros nove países. Recémformado, ingressou no CPARR/Fiocruz em dezembro de 1964, integrando o grupo do Prof. José Pellegrino, mestre admirável sempre lembrado por seus discípulos, aos quais deixou o legado de uma sólida e ampla formação científica. Dr. Naftale é chefe do

${ }^{25}$ Biografia baseada no curriculum vitae do pesquisador . 
Laboratório de Esquistossomose do CPqRR, após ter sido diretor deste centro de pesquisas por 12 anos, durante os quais promoveu seu crescimento e sua modernização. Tem sido consultor de vários comitês nacionais e internacionais, destacando-se como coordenador do crupo de Estudos sobre a Esquistossomose da OMS e da Fiocruz. É o atual diretor científico da Fundação de Amparo à Pesquisa do Estado de Minas Gerais (Fapemig). Tem contribuído para a formação de diversos pesquisadores e recebido vários prêmios nacionais e internacionais por sua relevante contribuição à ciência. 